\title{
Damage index estimation by analysis of meteorological disasters on film plastic greenhouses
}

\author{
Heeryong Ryu, Mankwon Choi", Myeongwhan Cho, Inho Yu, Seungyu Kim \\ (Protected Horticulture Research Institute, National Institute of Horticultural \& Herbal Science, Haman, 52054, South Korea)
}

\begin{abstract}
This study focuses on the analysis of the effect of meteorological disasters on film plastic greenhouses by typhoons, heavy snow, strong wind, and heavy rain. The data of meteorological disasters from 1998 to 2015 were analyzed on provincial basis to calculate the damage rate depending on the weather cause. The cumulative damage area is $20279 \mathrm{hm}^{2}$. The damage rates of typhoons, heavy snow, strong wind, and heavy rain are $46.4 \%, 47.4 \%, 2.5 \%$, and $3.8 \%$, respectively. The damage index of the greenhouse, which is the ratio of the greenhouse area to the cumulative damage area, was proposed to estimate the disaster risk for 17 administrative districts. The damage index data and the cumulative damage areas were divided using the Jenks' Natural Breaks method. The average damage index is 0.66 , and the damage indices are high in the metropolitan cities.
\end{abstract}

Keywords: damage index, global warming, heavy snow, strong wind, heavy rain, protected horticulture, typhoon, vinyl house DOI: $10.25165 /$ j.ijabe.20191205.4493

Citation: Ryu H R, Choi M K, Cho M W, Yu I H, Kim S Y. Damage index estimation by analysis of meteorological disasters on film plastic greenhouses. Int J Agric \& Biol Eng, 2019; 12(5): 58-63.

\section{Introduction}

With a value of $52526 \mathrm{hm}^{2}$ as of 2015 , the total greenhouse area in South Korea has rapidly increased since the introduction of plastic films and steel pipes in the 1970s. The greenhouse area has been stagnant in recent years after exceeding $50000 \mathrm{hm}^{2}$ in the early 2000s. However, the area has suffered an annual average loss of over $1000 \mathrm{hm}^{2}$ because of meteorological disasters, such as the heavy snowfall in Daegwallyeong in 2001, Typhoon Maemi in 2003, and Typhoon Bolaven in 2012. The most common damage caused by heavy snow is the collapse of pipes due to the inability to support the snow load. The damage caused by typhoons and strong winds mainly includes bent pipes, pulled columns, or torn covering materials. Meanwhile, the damages caused by heavy rain mainly include flooding of the cultivation facilities and crops caused by the overflow of water from drains around film plastic greenhouses, because guerrilla rainstorms will flow back into the film plastic greenhouses. The damages caused by heavy snow, typhoons, and other meteorological events increase the economic burden on farmers because of the decrease in productivity resulting from crop damage and the recovery cost for reinstallation. Until now, because of the large damage ability of snow and wind, the countermeasures to meteorological disasters in South Korea mainly focused on mitigating the damages caused by them. Studies on

\section{Received date: 2018-06-27 Accepted date: 2019-09-05}

Biographies: Heeryong Ryu, PhD, Scientific Researcher, research interests: finite element analysis and greenhouse structural design, Email: baradori@korea.kr; Myeongwhan Cho, MA, Scientific Researcher, research interests: greenhouse structural design and automation system. Email: phescho@korea.kr; Inho Yu, PhD, Scientific Researcher, research interests: greenhouse structural design and greenhouse ventilation system. Email: ihyu2003@korea.kr; Seungyu Kim, PhD, Scientific Researcher, research interests: horticultural science and greenhouse design. Email: kimsyu@korea.kr. *Corresponding author: Mankwon Choi, PhD, Postdoctoral Researcher, research interests: evaluation of structural performance of greenhouse and greenhouse structural design. Protected Horticulture Research Institute, Rural Development Administration, 1425, Jinhamro, Hamanmyeon, Hamangun, 52054, Gyeongsangnam-do, Rep. of Korea. Tel: +82-55-580-5553, Fax: +82-55-5805699, Email: choimk82@korea.kr. the countermeasures against snow suggested the installation of supplementary poles at the centers of single-span film plastic greenhouses ${ }^{[1,2]}$ and the structural reinforcement of rafters through bracing with a tension tie, steel wire, and pipes ${ }^{[3-5]}$. Meanwhile, studies on countermeasures against wind suggested structural safety analyses, structural reinforcement methods for the wind load of greenhouses with elevated eaves ${ }^{[6,7]}$, and methods of installing windbreak nets to reduce the wind speed around film plastic greenhouses $^{[8,9]}$. Furthermore, the covering can be tightly fixed with spiral steel pegs or fixing bands. In the case of heavy rain, Ryu et al. ${ }^{[10]}$ conducted a basic study on the structure-ground interaction response characteristics of greenhouse foundations under the weather conditions of strong winds and heavy rain.

Studies were also conducted on the development of safe greenhouses suitable for crop cultivation considering heavy rain, wind, and snow loads. Yu et al. ${ }^{[1]}$ investigated the specifications of a greenhouse for crop cultivation and developed a structurally embedded multi-span greenhouse that meets the design standards $^{[12,13]}$.

As mentioned earlier, even though disaster mitigation and prevention measures have been devised, meteorological disasters occur every year with varying conditions and intensities. Therefore, the causes of damages should be continuously investigated to prepare prevention and maintenance measures according to the meteorological disasters (i.e., typhoons, heavy snow, strong wind, and heavy rain). Park et al. ${ }^{[14]}$ classified the damages caused by meteorological disasters according to the cause and region, while Choi ${ }^{[15]}$ analyzed the characteristics of damages by meteorological disasters in the Korean Peninsula and Gyeongsangnam-do from 1985 to 2004 . Ahn et al. ${ }^{[16]}$ assessed the economic impact of meteorological disasters by comparing the frequency and the extent of damage caused by the disasters that occurred in the Korean Peninsula according to the cause over the long term with regard to the gross domestic product (GDP). Moriyama et al. ${ }^{[17]}$, Moriyama and Toyoda ${ }^{[18]}$, and Lee ${ }^{[19]}$ analyzed the causes and characteristics of damages through the greenhouse damage cases by typhoons, heavy snow, and strong wind. Meanwhile, Ryu et al. ${ }^{[20]}$ analyzed the effects of the greenhouse 
structural conditions on the structure performance through a load test and a finite element analysis considering the greenhouse actual load.

Previous studies focused on analyzing the status of meteorological disasters in terms of the infrastructure or the collapse characteristics of film plastic greenhouses. Thus, grasping the situation of national meteorological disasters in film plastic greenhouses and the extent of damages in each region according to different meteorological disasters was difficult. Therefore, this study analyzed the damaged area and the number of damages related to film plastic greenhouses by different meteorological disasters that occurred from 1998 to 2015. The disaster risk of each region was also estimated by calculating the ratio of the cumulative damaged area to the greenhouse area in each region to provide basic data for greenhouse renovation and facility complex formation projects and to establish efficient maintenance measures.

\section{Materials and methods}

The National Disaster Safety Portal ${ }^{[21]}$ provides statistics on disasters to help citizens make use of disaster reports published by the National Emergency Management Agency. Using the statistical data from 1998 to 2015, the damages caused by meteorological phenomena, such as typhoons, heavy snow, strong wind, and heavy rain, were regarded as a meteorological disaster. The meteorological disaster damage index of greenhouses caused by these damages was calculated.

According to the statistical data, the meteorological disaster data by cause are classified into 11 categories, including typhoons, heavy rain, heavy snow, earthquake, tsunami storm, heavy rain, typhoons, snowstorm, drought, strong wind, and wind wave. However, eight among these 11 categories, namely typhoons, heavy rain, heavy snow, windstorm, typhoon rain, snowstorm, strong wind, and wind wave, were targeted in this study. These categories are the main causes of damages to film plastic greenhouses. They were then classified again, based on similarity, into four categories (i.e., typhoons, heavy snow, strong wind, and heavy rain) to simplify the analysis. The re-categorization was done by grouping snowstorm with heavy snow, windstorm and wind wave with strong wind, and heavy rain and typhoon rain as typhoons.

In the case of the statistical data, the damages by meteorological disasters were categorized as refugees, fatalities, flooding, building, ship, farmland, crop, public facilities, and private facilities. The property damage (economic loss) data, which consisted of the damage count, damage area, and damage amount, were provided based on this classification. Only the film plastic greenhouses belonging to private facilities were analyzed in this study.

Among the statistical data, the damaged area in 2003 was more than five times larger than the total greenhouse area in South Korea (i.e., approximately $52000 \mathrm{hm}^{2}$ ). Thus, this statistical data was regarded as erroneous, and the separate data was used only for the damaged areas of Gimhae and Sancheong in the Gyeongnam province in 2003. The damage data obtained from the Gimhae Agricultural Technology Center and the information provided by Lee et al. ${ }^{[22]}$ was used for the Gimhae and Sancheong regions.

The damage index was calculated as follows:

$$
\mathrm{DI}=\mathrm{CDA} / \mathrm{RGA}
$$

where, DI is the damage index; CDA denotes the cumulative disaster area for the analysis period, and RGA stands for the regional greenhouse area in 2015 .
The 2015 film plastic greenhouse area data from the greenhouse status and vegetable production statistics yearbook published by the Ministry of Agriculture, Food and Rural Affairs ${ }^{[23]}$ (MAFRA) was used for the greenhouse area data of South Korea.

The damage index data (Figures 3 and 4) and the cumulative damage areas (Figure 2) calculated using Equation (1) was divided into 5 and 10 grades, respectively, using the Jenks' Natural Breaks method provided in ArcGIS 10.2.2. The Jenks' Natural Breaks method classifies the most similar values into the same grade. In this graph, the closer the value is to red, the higher the damage index; and the closer the value is to green, the lower it is.

\section{Results and discussion}

\subsection{Meteorological Disasters and Total Damage Index}

The analysis of the status of meteorological disasters of film plastic greenhouses caused by typhoons, heavy snows, strong winds, and heavy rains is described in this section. The total damage area during the research period (1998-2015) was $20279 \mathrm{hm}^{2}$, while the total damage amount was KRW 1381 billion. Figure 1 shows the damaged area and the amount of film plastic greenhouses according to the cause of the meteorological disaster by year. Figure 2 presents the cumulative damaged area of the meteorological disasters by typhoons, heavy snow, strong wind, and heavy rain by city and province. The damage area ratios by cause were $46.7 \%$ for typhoons, $47.3 \%$ for heavy snow, $2.3 \%$ for heavy wind, and $3.7 \%$ for heavy rain, while the damage amount ratios were $40.1 \%, 54.0 \%, 3.7 \%$, and $2.2 \%$, respectively. Thus, wind and snow were the main causes of damages throughout the year (Table 1).

The regions with large greenhouse area were inevitably subject to large damages by meteorological disasters across the country. Therefore, the ratio of the cumulative disaster area to the greenhouse area was set as the damage indicator of the metropolitan city and the province to examine the disaster risk by region according to standard values. In addition, the damage index (Equation (1)) was calculated according to the cause of damage.

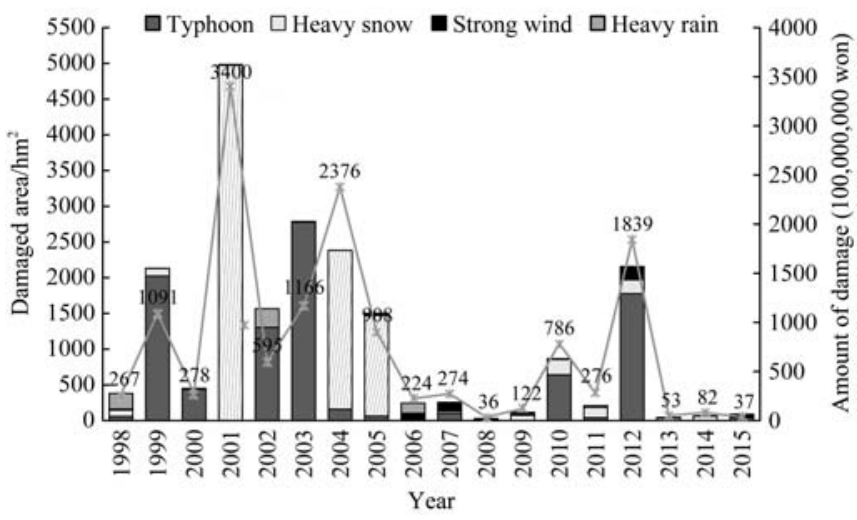

Figure 1 Damaged area (accumulative histogram) and amount (broken line) of film plastic greenhouses caused by meteorological disasters by year

Table 1 Damage area and amount of the meteorological disasters of film plastic greenhouses by causes from 1998 to 2015

\begin{tabular}{ccc}
\hline Cause & Damage area (ha) & Amount of damage (100 000 000 won) \\
\hline Typhoon & 9401 & 5534 \\
Heavy snow & 9605 & 7452 \\
Strong wind & 508 & 311 \\
Heavy rain & 764 & 513 \\
Sum & 20279 & 13810 \\
\hline
\end{tabular}




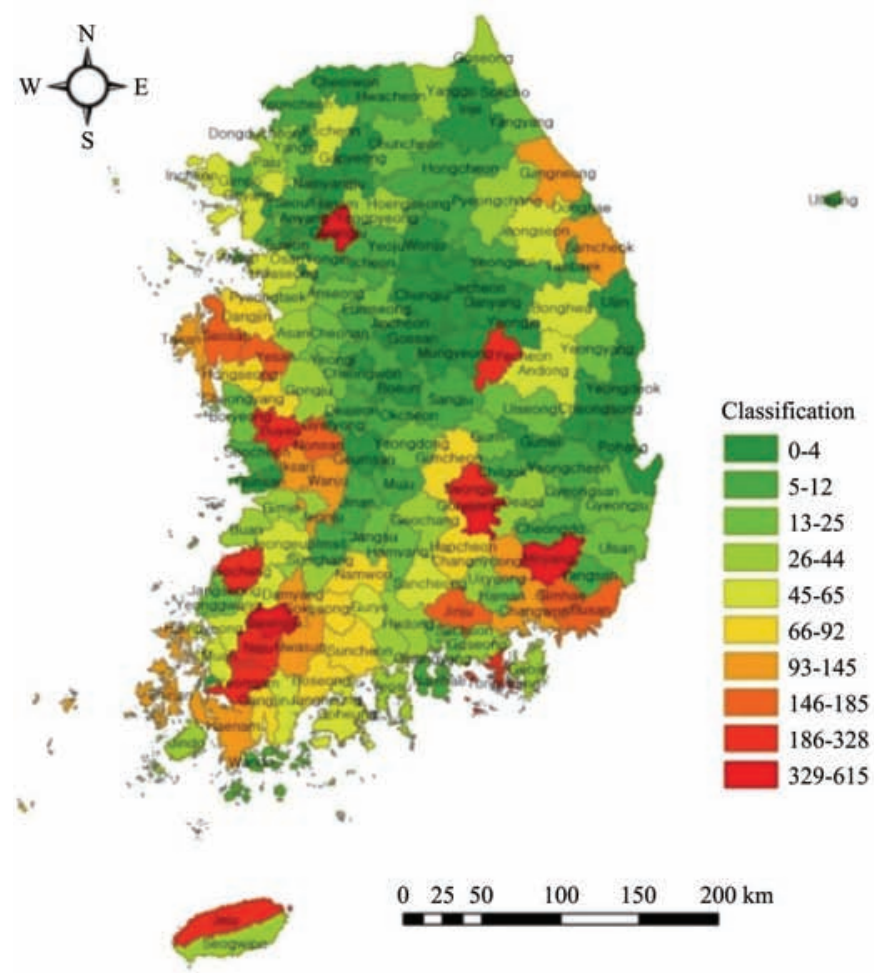

a. Typhoons

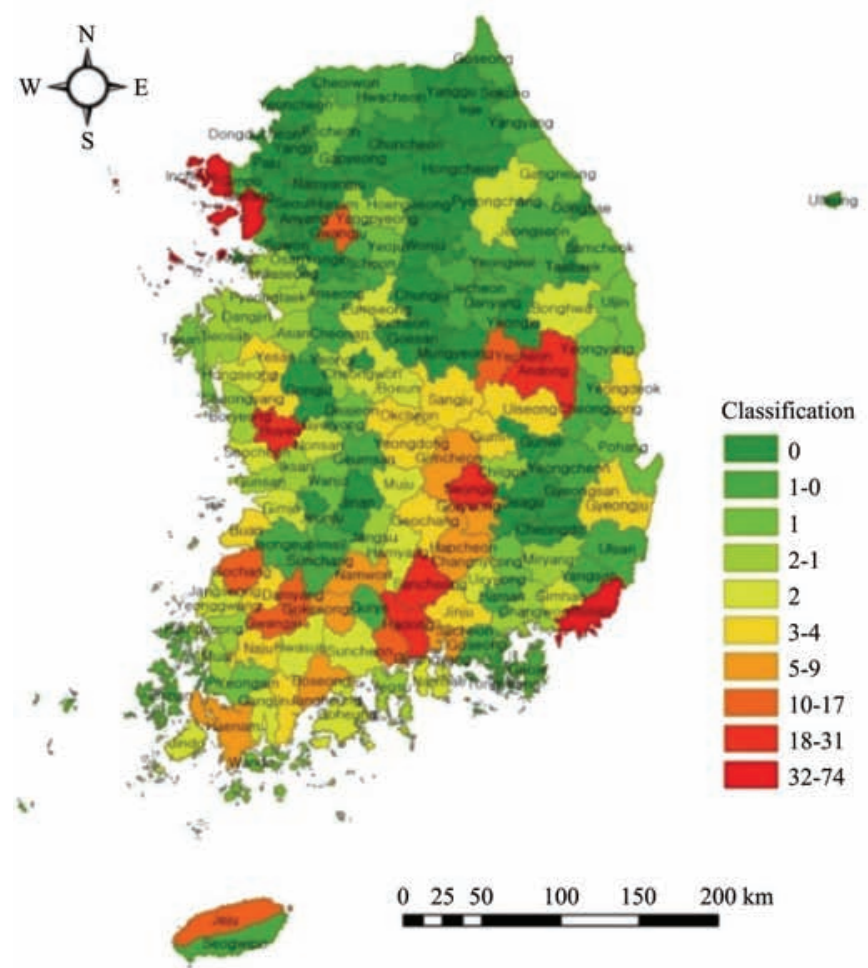

c. Strong wind
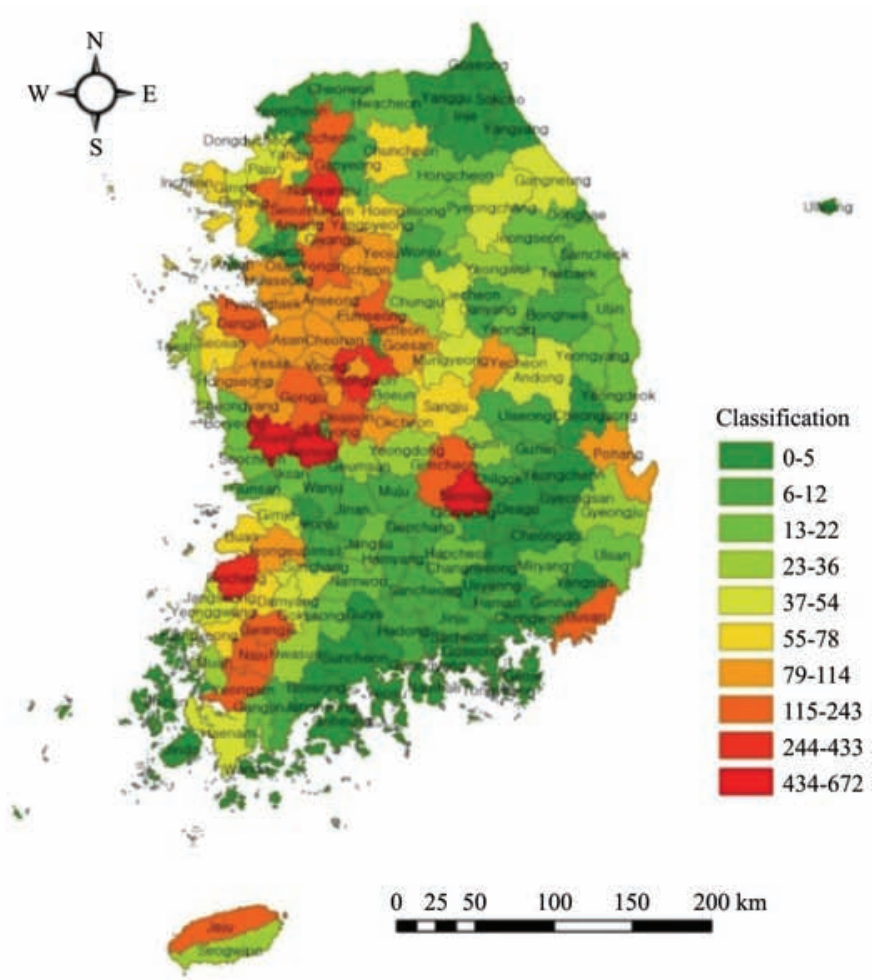

b. Heavy snow

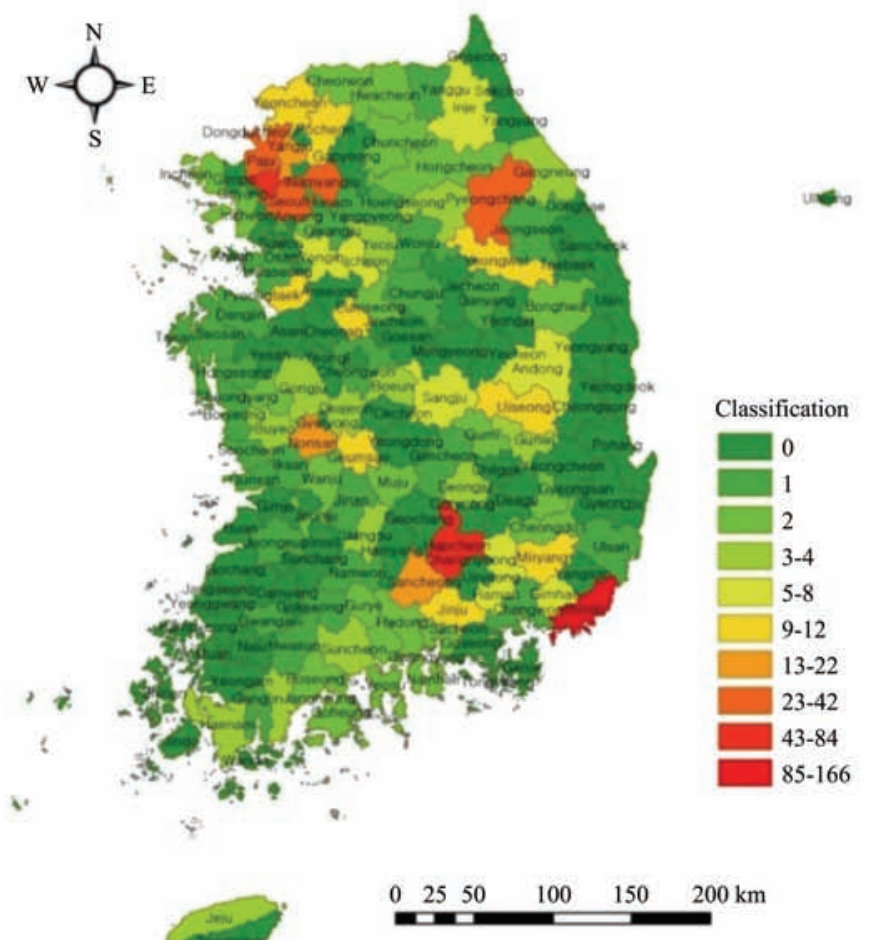

d. Heavy rain

Figure 2 Cumulative damaged area in cities and provinces caused by typhoons, heavy snow, strong wind, and heavy rain from

1998 to 2015

Figure 3 shows the damage index according to the total cumulative damage area caused by typhoons, heavy snow, strong wind, and heavy rain. A greater damage index indicated relatively more damages suffered by the meteorological disasters for the 18 years of the data analysis period. The damage index for the metropolitan city was 1.76 in Seoul, 1.01 in Gwangju, 0.98 in Daejeon, and 0.95 in Busan, whereas that by province ranged from 0.00 to 0.5 . The average damage index for 17 regions, including metropolitan cities and provinces, was approximately 0.66 . Among the regions, the damage index of the Jeju region has the highest value of 2.58 because the greenhouse area of the region did not include the cultivation area of citrus fruits for calculation. No greenhouse damage area was found in Sejong City because of changes in the administrative district. Hence, its damage index was zero. 


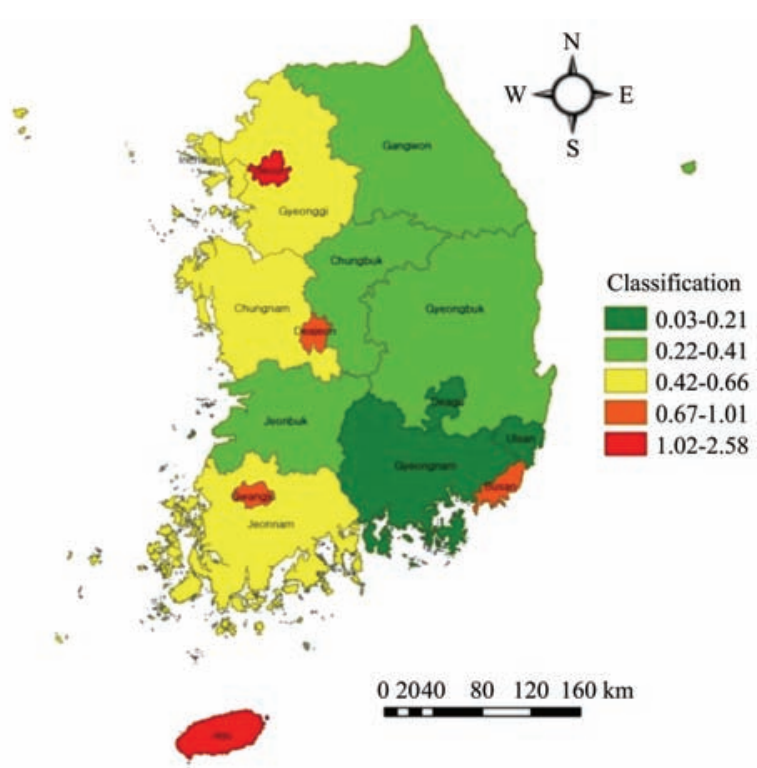

Figure 3 Damage index caused by meteorological disaster for each area
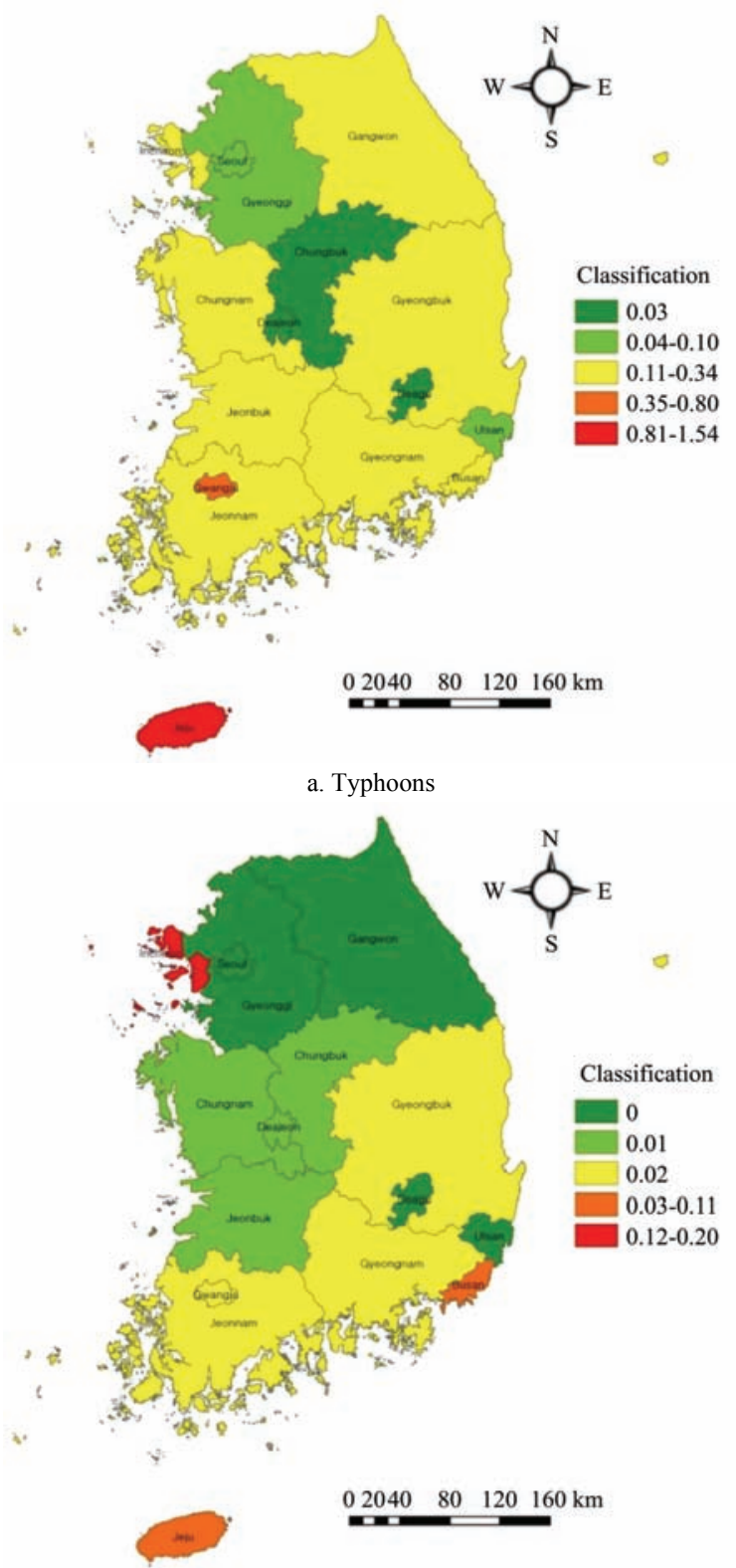

c. Strong wind

\subsection{Damage Index by Cause}

According to the causes of meteorological disasters, the top three regions with the highest damage indices caused by typhoons were Jeju, Gwangju, and Jeonnam, which were $1.54,0.80$, and 0.34 , respectively. The damage indices of the rest ranged from 0.00 to 0.28 (Figure 4a). The reason for the high damage index in Jeju region is that it is located in the path of typhoons and is therefore susceptible to damages by typhoons. Furthermore, even though the Gyeongbuk and Gyengnam regions suffered large damages from Typhoon Maemi in 2003, the damage indices of Gwangju and Jeonnam were high because they suffered large damages from typhoons Olga (1999), Lusa (2002), and Bolaven (2012). These results suggested that the damages varied greatly according to the typhoon path (Figure 5). The damages of the film plastic greenhouses concentrated in major horticultural complexes located on the typhoon paths of one to three large typhoons.

The top three regions with the largest damage indices caused by heavy snow were Seoul, Jeju, and Daejeon, which were 1.39, 0.95 , and 0.94 , respectively. The damage indices of the rest ranged from 0.00 to 0.37 (Figure $4 b$ ). The damage index of Seoul
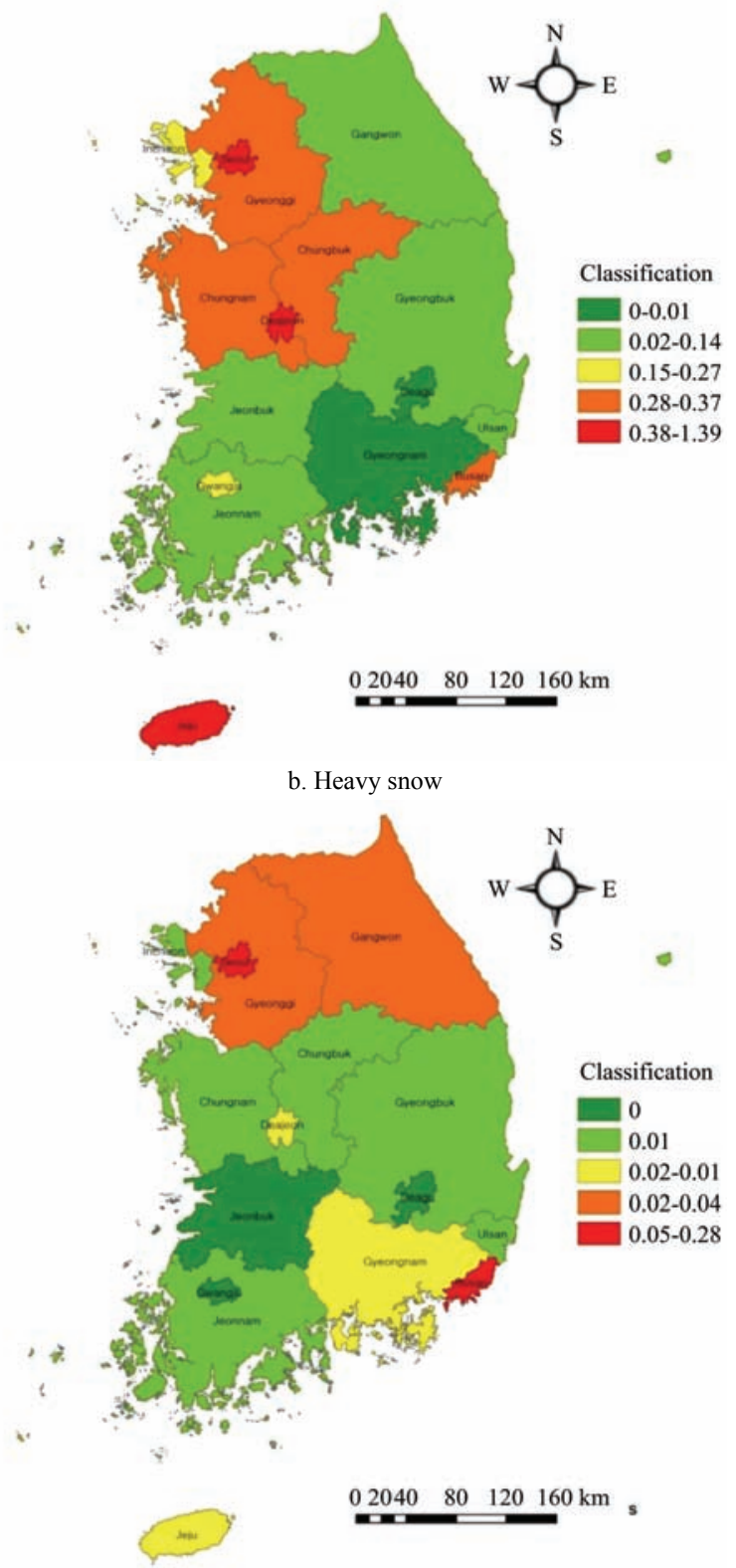

d. Heavy rain

Figure 4 Damage index in different regions caused by typhoons, heavy snow, strong wind, and heavy rain 


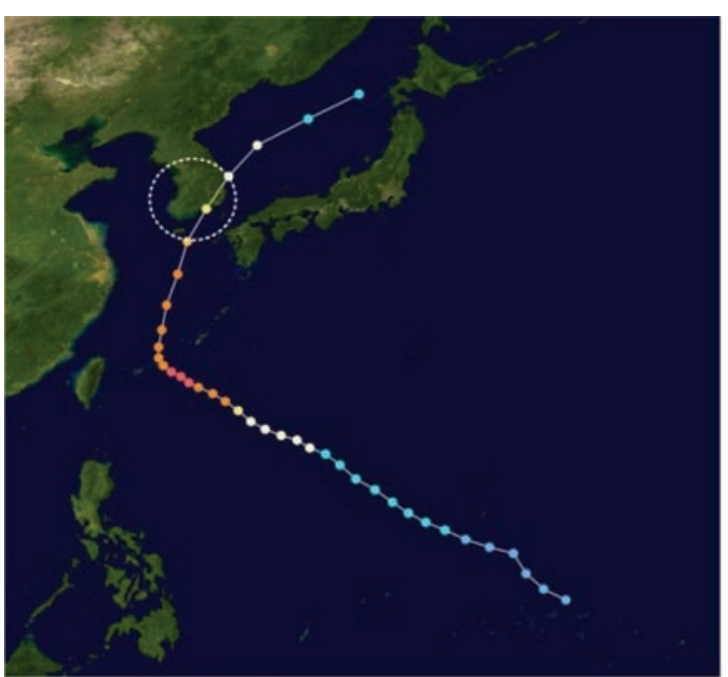

a. Maemi

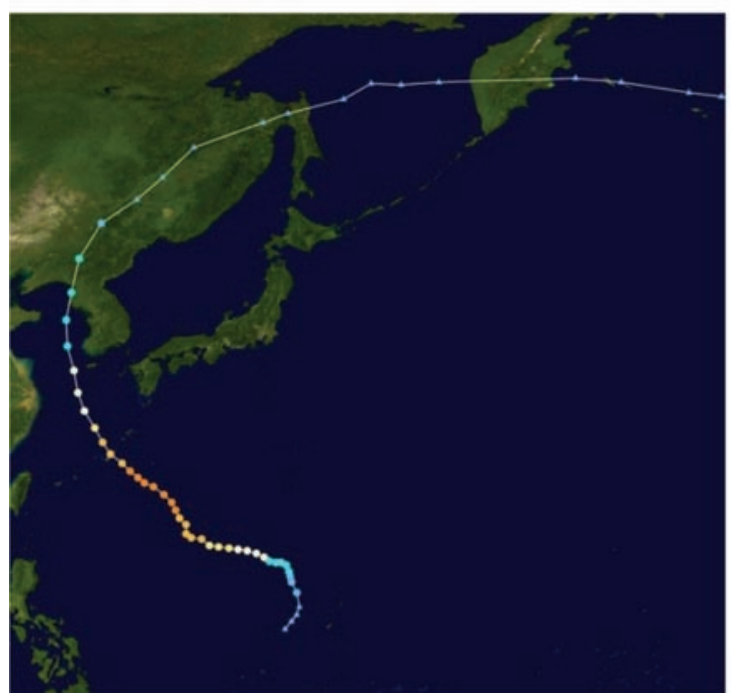

c. Bolaven

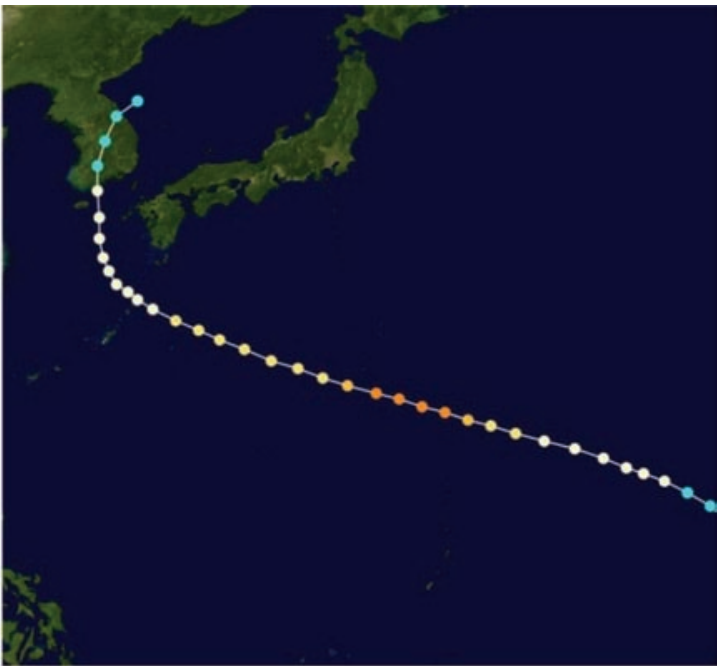

b. Rusa

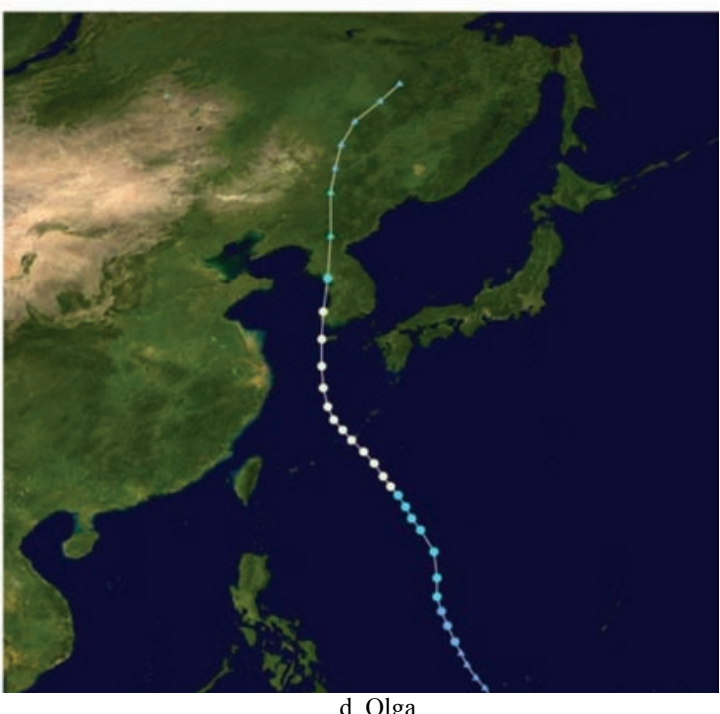

d. Olga

Figure 5 Typhoon path: Maemi, Rusa, Bolaven, and Olga (Source: www.ko.wikipedia.org)

was large because it had a smaller greenhouse area compared to those of the other regions. The damage indices of the Daejeon, Chungbuk, and Chungnam regions were large because of the greenhouse damages caused by heavy snow in the central region on March 4, 2004 ${ }^{[24]}$. The Gangwon province showed a smaller damage index than Gyeongnam and Jeju despite Gangwon having much more snow every year than the other two regions. The reason for the small index seemed to be that, considering the regional characteristics, they prepared sufficiently for heavy snow in advance. As described earlier, the degree of damages varied depending on the shape and maintenance of the greenhouse even if the facilities were located in a major controlled horticultural complex. Therefore, systematic maintenance through proper repair and reinforcement is required to reduce meteorological disasters. Furthermore, new greenhouses should be constructed according to the regional design standards of the design and construction code on horticultural and herbal facilities for disaster resistance ${ }^{[25]}$.

The top three regions with the largest damage indices caused by strong winds were Incheon, Busan, and Jeju, which were 0.20, 0.11 , and 0.08 , respectively. The damage indices of the rest ranged from 0.00 to 0.02 (Figure $4 \mathrm{c}$ ). The damage index of the Incheon region was large because of the damage caused by the local gust on April 2, 2015 ${ }^{[26]}$. The Busan and Gyeongnam regions showed large damage indices because of the strong winds occurred on March 28, 2007 ${ }^{[27]}$ and April 3, 2012 $2^{[28]}$. In the case of typhoons and heavy snow, even one strong wind was found to cause damages to many greenhouses. Therefore, it is necessary to develop greenhouse design technology and systematic maintenance to prevent such sudden damages caused by a single strong wind.

The top three regions with the largest damage indices caused by heavy rain were Seoul, Busan, and Gyeonggi, which were 0.28, 0.25 , and 0.04 , respectively. The damage indices of the rest ranged from 0.00 to 0.02 (Figure $4 \mathrm{~d}$ ). The frequency of meteorological disasters has been increasing in recent years because of the abnormal climate. However, the damage index by heavy rain was smaller than those of wind (typhoon + strong wind) and snow (heavy snow). Thus, there is a need for a greenhouse design method that can consider wind and snow in detail.

Except for the Daegu and Ulsan metropolitan cities, the damage indices of Seoul, Busan, Incheon, Gwangju, and Daejeon were larger than those of the other eight regions even though their greenhouse areas were smaller. In other words, these regions had a greater risk of greenhouse disasters compared to the other regions. The greenhouse maintenance in these regions, such as the daily preparations against typhoons and heavy snow, is estimated to become insufficient.

Therefore, plans should be prepared to select a model suitable for local design standards and reduce the damage index if new greenhouses are to be constructed in these regions in the future. 
Furthermore, maintenance and reinforcement should be performed in accordance with the design standards of each region through the systematic maintenance of greenhouses.

\section{Conclusions}

This study analyzed the meteorological damage area and amount of damage related to film plastic greenhouses and calculated the damage index of each region, that is, the ratio of the cumulative damaged area to the greenhouse area. Consequently, the ratios of the total damage areas for typhoons, heavy snow, strong wind, and heavy rain during the analysis period 1998-2015 were $46.4 \%, 47.4 \%, 2.5 \%$, and $3.8 \%$, respectively, totaling 20279 $\mathrm{hm}^{2}$. Thus, the damage ratios of winds (typhoon + strong wind) and snow were similar.

The average damage index for the 17 administrative districts was calculated from the cumulative damage area against the greenhouse area, which was 0.66. Regions such as metropolitan cities with no horticultural complexes showed large greenhouse damage indices. These regions should raise awareness about the response to meteorological disasters and take systematic preparatory measures to reduce the risk of greenhouse disasters. Furthermore, disaster prevention specifications that meet the local design standards must be selected, designed, and constructed to reduce the greenhouse damage index. In addition, techniques to prevent damages should be developed to avoid the potential for large damages caused by a single large meteorological disaster.

\section{Acknowledgements}

This work was carried out with the support of "Research Program for Agriculture Science \& Technology Development (PJ011397)" Rural Development Administration, Republic of Korea.

\section{[References]}

[1] Kim J Y. Damage status and countermeasure against snowfall on plastics houses. Korean Journal of Horticultural Science \& Technology, 2001; 19(4): 629-635.

[2] Yum S H, Kim S H, Lee S B, Kim M Y, Kim C S. Effect of a supplementary pole on the structural stability in the single-span plastic greenhouses. Journal of Bio-Environment Control, 2010; 19(2): 63-69.

[3] Kim B K, Lee S H, Kim J W, Shin K J. Collapse prevention method of long-span plastic greenhouse for heavy snow. Journal of Korean Society of Steel Construction, 2010; 22(1): 67-74.

[4] Jung D J, Teng C. Effect of wire bracing to snow load acting on vinyl house frame. Journal of the Korean Institute of Rural Architecture, 2010; 12(3): 27-34

[5] Shin K J, Shin D H, Lee S H, Chae S H. Reinforcement method of a long span plastic greenhouse using Tension-tie. Journal of Korean Society of Steel Construction, 2011; 23(1): 41-49.

[6] You H Y, Paek Y, Kim H J, Chun H, Yu I H. A study on structural behaviour characteristics of high-rise improved 1-2W vinyl-house for paprika cultivation. Proceeding of Bio-Environment Control, 2007; 16(2): 42.

[7] Ryu H R, Yu I H, Cho M W, Um Y C. Structural reinforcement methods and structural safety analysis for the elevated eaves height 1-2W type plastic greenhouse. Journal of Bio-Environment Control, 2009; 18(3): 192-199.

[8] Yum S H, Kim C S, Choi Y D. Analysis of the structural safety of a wind-protecting wall using Ansys/Cfx. Journal of Bio-Environment Control, 2006; 15(2): 138-148.

[9] Yum S H, Kang S-H. An experimental study on characteristics of pressure drop of screens used in horticultural facilities. Journal of the Korean Society of Agricultural Engineers, 2013; 55(6): 31-35.

[10] Ryu H R, Cho M W, Yu I H, Moon D G. Finite element modeling for structure-soil interaction analysis of plastic greenhouse foundation. Korean Journal of Agricultural Science, 2014; 41(4): 455-460.

[11] Yu I H, Lee E H, Cho M W, Ryu H R, Kim Y C. Development of multi-span plastic greenhouse for tomato cultivation. Journal of Bio-Environment Control, 2012; 21(4): 428-436.

[12] Yu I H, Lee E H, Cho M W, Ryu H R, Gyung M D. Development of single-span plastic greenhouses for hot pepper rainproof cultivation. Protected Horticulture and Plant Factory, 2013; 22(4): 371-377.

[13] Yu I H, Lee E H, Cho M W, Ryu H R, Moon D G. Development of rain shelter for chinese cabbage rainproof cultivation. Protected Horticulture and Plant Factory, 2014; 23(4): 293-302.

[14] Park J K, Jang E S, Choi H J. An analysis of meteorological disasters occurred in the korean peninsula. Journal of the Environmental Science International, 2005; 14(6): 613-619.

[15] Choi H J. Review of risk model and application of the prevention meteorological information to reduce the natural disasters. Master's degree thesis, Kimhae: Inje University, 2007, 2: 17.

[16] Ahn S H, Park K J, Kim J Y, Kim B J. The characteristics of the frequency and damage for meteorological disasters in Korea. Journal of Korean Society of Hazard Mitigation, 2015; 15(2): 133-144.

[17] Moriyama H, Sase S, Kowata H, Ishii M. Engineering analysis of the greenhouse structures damaged by typhoon 0221 in Chiba and Ibaraki. Journal of SASJ, 2003; 34(3): 199-212.

[18] Moriyama H, Toyoda H. Characteristics of greenhouses by heavy snow in January 1998 in Southern Tohoku area. Journal of SASJ, 1999; 30(2): 205-214.

[19] Lee S G. Destruction shapes and structural safety of greenhouses by strong wind. Korean Journal of Horticultural Science \& Technology, 2001; 19(4): 623-628.

[20] Ryu H R, Lee E H, Cho M W, Yu I H, Kim Y C. Evaluation on the behavioral characteristics of plastic greenhouse by full-scale testing and finite element analysis. Journal of Bio-Environment Control, 2012; 21(4): 459-465.

[21] Ministry of Public Safety and Security (MPSS). Statistical Yearbook of Natural Disaster Sejong: MPSS. 2017. http://www.safekorea.kr/ idsiSFK/367/menuMap.do?w2xPath=/idsiSFK/wq/sfk/cs/csc/bbs_conf.xml \&bbs_no=26. Accessed on [2017-01-09].

[22] Lee S Y, Kim H J, Yum S H, Kang Y I, Chun H, Nam Y I. Investigation and analysis of damaged single-span greenhouse by Typhoon 'Maemi'. Proceedings of the Korean Society for Bio-Environment Control Conference, 2005.

[23] Ministry of Agriculture Food and Rural Affairs (MAFRA). Annals of Greenhouse Status and Vegetables Production in Korea. Gwacheon: MAFRA, 2015. http://library.mafra.go.kr/skyblueimage/25004.pdf. Accessed on [2017-01-09].

[24] Korea Meteorological Administration (KMA). Annual Climatological Report. Seoul: KMA. 2004. http://www.kma.go.kr/repositary/sfc/pdf/ sfc_ann_2004.pdf. Accessed on [2017-01-09].

[25] Ministry of Agriculture Food and Rural Affairs (MAFRA) and Rural Development Administration (RDA). Design and Construction Code on Horticultural and Herbal Facilities for Disaster Resistance. Gwacheon and Jeonju: MAFRA \& RDA. 2014. http://www.nongsaro.go.kr/portal/ contentsFileView.do? cntntsNo=89218\&fileSeCode $=185001 \&$ fileSn $=1$. Accessed on [2017-01-09].

[26] Korea Meteorological Administration (KMA). Annual Climatological Report. Seoul: KMA. 2015. http://www.kma.go.kr/repositary/sfc/pdf/ sfc_ann_2015.pdf. Accessed on [2017-01-09].

[27] Korea Meteorological Administration (KMA). Annual Climatological Report. Seoul: KMA. 2007. http://www.kma.go.kr/repositary/sfc/pdf/ sfc_ann_2007.pdf. Accessed on [2017-01-09].

[28] Korea Meteorological Administration (KMA). Annual Climatological Report. Seoul: KMA. 2012. http://www.kma.go.kr/repositary/sfc/pdf/ sfc_ann_2012.pdf. Accessed on [2017-01-09]. 